\title{
Development of linguistic institutional educational virtual environment at Moscow State Linguistic University (2016-2018)
}

\author{
Innara A. Guseynova ${ }^{1}$, Alexey I. Gorozhanov ${ }^{2, *}$, and Elena F. Kosichenko ${ }^{3}$ \\ ${ }^{1}$ Vice Rector's Office, Moscow State Linguistic University, 38, Ostozhenka, 119034, Moscow, Russian Federation \\ ${ }^{2}$ Laboratory for Fundamental and Applied Issues of Virtual Education, Moscow State Linguistic University, 38, Ostozhenka 119034 \\ Moscow, Russian Federation \\ ${ }^{3}$ Department of General and Comparative Linguistics, Moscow State Linguistic University, 38, Ostozhenka 119034 Moscow, Russian \\ Federation
}

\begin{abstract}
Within the framework of The Government Contract (№ 214/102, № 27.9307.2017/БЧ) on the basis of E-Learning Centre, now the Laboratory for Fundamental and Applied Issues of Virtual Education at Moscow State Linguistic University there has recently been developed an institutional educational environment (IEVE) for commercial purpose, which consists of nodes - LMS Moodle foreign language courses. The aim of the programme is to devise a commercial model of distance teaching foreign languages that will secure an effective and efficient learning. Successful implementation of about twenty educational programmes of distance learning at MSLU has proved the effectiveness of management and the important role of information gathering with the aim of further expertise. For that purpose special software has been developed. Then some statistic data are given, proving the relevance of courses in different languages, monthly fluctuation of agreement making, the relevance of different types of courses, the relative percentage of students with more than one agreement ect. The results give reasons to believe that in terms of development prospects the major focus in the near future will be placed on increasing the number of taught languages and expanding the variety of educational programmes (with an important step being launching a programme of Russian as a foreign language), upgrading software products with a view to improving distant learning management.
\end{abstract}

\section{Introduction}

The digital era calls for updating educational programmes and for their deployment in a totally new educational environment that has already received a number of names, like 'virtual', 'electronic', 'computer', 'digital', etc [1, 2, 3, 4]. The large number of synonyms points both to the dynamic development of the educational environment and to its mobility. In this article we use the term 'virtual' as it implies the variety of linguistic means and electronic resources that provide technical support to the content and serve to visualize the verbal information.

The terms 'dynamic' and 'mobile' are crucial to this research as they reveal the most essential aspects of the virtual environment. The dynamic component is the underlying element of any functional system and forms the binary opposition dynamics - stability, whereas mobility points to movement in the time-space continuum. Dynamics reflects the gradual development of the system with mobility indicating to transformation from one state to another, or a transfer from one sphere to another. The idea of mobile borders and their fluidity is often referred to in theories of discourse, including the different kinds of institutional discourse, like mass media, economic, political, marketing, advertising, pedagogical, ecological and other generally recognized types of discourse and those seeking an independent linguistic status. This goes to explain the wide usage of the term shift in linguistic concepts, like semantic shift, shift in meaning, cognitive shift $[5,6,7]$. Thus, it is clear that institutional discourse is characterized by fluidity, flexibility, blurring borders, susceptibility to change and tendency for transformation and mimicry.

The outlined features of institutional discourse are crucial for this research which is not merely theoretical but has significant practical implications. Firstly, the content of education can be placed in the virtual environment and supplied with means of visualization that are effective if maintained by electronic environment resources. This kind of support makes the learning process much easier and fosters remembering information by the recipient as it targets different senses. Secondly, the content can adapt to the recipient's current demands without being affected much and thus preserving its high quality. Thirdly, the recurrence of the virtual institutional discourse provides the opportunity to do revision and make corrections of mistakes at any time thus, encouraging the recipient to achieve new results, to excel his knowledge and improve his learning abilities.

* Corresponding author: a_gorozhanov@mail.ru 
no less decisive factor is the difference between the virtual institutional educational environment and online learning. In this regard it seems important to describe the specific features of both phenomena and to determine the approaches to online learning with reliance on the existing teaching and learning practices.

It's common knowledge that today a high level of foreign language proficiency increases job opportunities and applicants' competitiveness on the job market and helps to solve practical tasks that emerge in the course of cross-cultural interaction. This circumstance has triggered two tendencies that require explanation in terms of the differences between the virtual educational environment on the one hand and large-scale online teaching on the other hand. The crucial difference is that large-scale online teaching targets the mass recipient who expects to be entertained and to have a pleasant leisure time while dealing with the information he gets. Institutional educational space suggests that the recipient should improve his qualification and professionalism, which makes this kind of space rather unique as it takes into account two factors, namely the factor of professional occupation and the specificity of professional activity of each concrete person.

Thus, we have ground to conclude that large-scale online teaching transforms education, which is basically a social, cultural and historical phenomenon into a consumer good, noticeably devaluing it in this way. This results in lower educational standards, pseudoaccessibility to the content and the recipient's quite groundless confidence in his high competence. With this tendency in view massive online teaching can be regarded as a preliminary stage of education that encourages the person's interest in some content, or in a subject. Interpreted in this way massive online teaching should be studied as part, or a stage of continuous learning that has a long scientific tradition both in the Russian Federation and in other countries.

In this article we develop an innovative approach to education as a social institution and aim to revise and share the experience we have gained in developing mechanisms that secure the inclusion of foreign language teaching in the virtual educational environment.

\section{Problem statement}

Within the framework of The Government Contract (№ $214 / 102$, № 27.9307.2017/БЧ) on the basis of ELearning Centre, now the Laboratory for Fundamental and Applied Issues of Virtual Education at Moscow State Linguistic University there has recently been developed an institutional educational environment (IEVE) for commercial purpose, which consists of nodes - LMS Moodle foreign language courses.

The aim of the programme is to devise a commercial model of distance teaching foreign languages that will secure an effective and efficient learning. The system relies on the principle of individual approach, which suggests replacement of learning in groups by the scheme 'one student - one teacher' [8, p. 3].
Both factors - commercial learning and the individual approach - are closely related, as having to pay for education the student expects more attention from the teacher. Online group learning cannot meet the student's expectations as the participants in the group usually have different levels of language proficiency and, living in different time zones, may have difficulty with attending group webinars at regular hours.

With this in view there has been worked out a system of solutions that will serve to organize a proper teaching structure, choose appropriate teaching methods, devise LMS Moodle courses and adjust them to teaching foreign languages.

By December 2018 the following additional education programmes had been developed and implemented (in the alphabetic order):

- A Communicative Grammar of English (advanced level of English)

- A Communicative Grammar of German (advanced level of German)

- A Course in English (for beginners)

- A Course in English (for advanced learners)

- A Course in Spanish (for beginners)

- A Course in Spanish (for advanced learners)

- A Course in German (for advanced learners)

- A Course in French (for beginners)

- A Course in French (for advanced learners)

- A Course in French (for advanced learners 2)

- Written Translation of Mass Media Texts (advanced level of English). Stage I. Language, Education, Arts

- Written Translation of Mass Media Texts (advanced level of English). Stage II. Society, Economics, Environment

- Written Translation of Mass Media Texts (advanced level of Spanish). Stage I. Politics, Society, Education

- Written Translation of Mass Media Texts (advanced level of Spanish). Stage II. Politics, Economics, Sports

- Written Translation of Mass Media Texts (advanced level of German). Stage I. Culture and Arts, Education, Travelling, Innovations

- Written Translation of Mass Media Texts (advanced level of German). Stage II. Economics, Environment, Scientific Research, Innovations

- Written Translation of Mass Media Texts (advanced level of French). Stage I. News Press, Education, Problems of French Youth

- Written Translation of Mass Media Texts (advanced level of French). Stage II. Global Problems of Today

- Difficulties of English Grammar in an Authentic Text

- Difficulties of German Grammar in an Authentic Text

The educational programmes 'Difficulties of English Grammar in an Authentic Text' and 'Difficulties of German Grammar in an Authentic Text' are retraining programmes ( 72 hours / 2 credit hours). 
Successful implementation of the enlisted educational programmes of distance learning at MSLU has proved the effectiveness of management and the important role of information gathering with the aim of further expertise. It has been experimentally proved that without specialized software programmes planning future work may be hindered. The reason is that, when the system is used as an IEVE node, the LMS Moodle protocoling subsystem cannot meet the requirements of a concrete organization to filling out paperwork. To meet the challenges and overcome the problem it was highly important to define objectives aimed at raising the efficiency of management and increasing the quality of analyzing the process and the results of online teaching foreign languages in the IEVE.

The objectives are as follows:

- Record of all teachers and students.

- Record of all implemented educational programmes (courses).

- Record of teachers' engagement in teaching a certain course.

- Record of each current agreement.

- Monthly record of the work done by each teacher.

- Monthly record of supervision of each educational programme.

- Record of the current and performed agreements.

- Compiling monthly reports.

- Compiling statistics reports.

\section{Software Development}

The chosen instrument of developing the application was Python programming language (version 3), graphical library PyQt5 and the data base SQLite. As a result, a stable improved version of a standalone application with a graphical user interface was created. tables:

The data base of the application consists of five

- authorized - records of teacher's admission to educational programmes;

- course - records of implemented courses;

- courses for teacher - records of current agreements;

- student - records of students;

- teacher - records of teachers.

The table 'authorized' has the following columns:

- id - a unique record identifier;

- teacher - a unique record identifier of the teacher table;

- course - a unique record identifier of the course table;

- limit date - the closing date in the YYYY-MM-DD

(further on all dates are used in this format).

The 'course' table has the following columns:

- id - a unique record identifier;

- coursename - the full name of the course;

- coursevolume - the volume of the course in hours;

- courseVC - the number of online consultations in the videoconference mode;

- courseWT - the number of open tasks;
- courseprice - the course fees;

- courseVCprice - the payment to the teacher for one consultation in the videoconference mode;

- courseWTprice - the payment to the teacher for assessing one open task;

- courseManaging - the payment to the supervisor of the educational programme;

- courseshort - a short name of the course;

- courseLang - the language of the given course.

The table 'coursesforteacher' has the following columns:

- id - a unique record identifier;

- active - a note of the course being active or inactive (record of the current and performed agreements);

- course - a unique identifier of the record from the course table;

- teacher - a unique identifier of the record from the teacher table;

- student - a unique identifier of the record from the student table;

- examiner - a unique identifier of the record from the teacher table;

- agreement - the number of the agreement;

- agreemdate - the date of the agreement;

- startdate - the starting date of the course;

- duration - the duration of the course;

- examdate - the date of the examination;

- certificate - the date of getting the Certificate;

- certnumber - the number of the Certificate;

- extra - extra information;

- discount - the level of discount;

- price - the education fees under agreement;

- addconsultprice - the fee for one extra consultation in the videoconference mode;

- addconsultquant - the number of the paid extra consultations in the videoconference mode.

The table 'student' has the following columns:

- id - a unique identifier of the record;

- famname - student's family name;

- name - student's first name;

- fathname - the student's middle name;

- phone - the student's phone number;

- email - the student's e-mail;

- dateofbirth - the student's date of birth;

- passport - the student's passport number;

- extra - extra information.

The table 'teacher' has the following columns:

- id - a unique identifier of the record;

- famname - the teacher's family name;

- name - the teacher's name;

- fathname - the teacher's middle name;

- phone - he teacher's telephone number;

- position - the teacher's position at the university;

- email - the teacher's e-mal;

- extra - extra information.

Once the programme is launched tables of record of current and performed agreements are created. Each table has the following columns: 
- id - a unique identifier of the record;

- month - the reference month;

- vconf - the number of consultations in the videoconference mode during the reference month;

- opentask - the number of the assessed open tasks during the reference month;

- managing - payment to the supervisor of the educational programme during the reference month.

If, for example, the duration of a course under the agreement is 120 days with 1 September, 2016 being the beginning date, the table will contain ten rows (four rows for each month under the agreement plus six spare months to account for unforeseen circumstances). The spaces in the columns 'vconf', 'opentask' and 'managing' will stay unfilled, whereas the vertical cell month will be filled with the names of the months starting with the beginning of the course (in YYYYMonth format).

The interface of the application contains menu items (File, Courses, Students, Teachers, Financial, Help). The main widget of the application has seven tabs (Courses, Students, Teachers, Authorized, CST, CST Tables, Reports).

Clicking on the tabs Courses, Students, Teachers, Authorized and CST shows the content of the respective table ('course', 'student', 'teacher', 'authorized' or 'coursesforteacher').

Over the table the button for adding a new record is placed. All tables have vertical and horizontal scroll bars, and all columns are sortable.

The 'CST' table not only shows the data but analyses them. When the cursor is pointed to the duration cell the number of days - starting with the first class and up to the current date - is shown. If the term of the course has expired the respective cell is coloured red. If the cell of the exam date is filled but the cell of the final date of the course is not, it is coloured red, too. Thus, keeping track of the agreement status and of certificate issue date is quite easy.

Likewise, the Teacher tab reflects information about admission of teachers to this or that course, shows the remaining days and uses the red background colour to indicate the end of this period (with the number of the remaining days below 61).

The CST Tables tab consists of automatically created tables that contain information about work under agreement and some other information. These tables are arranged in form of tabs, each of which is marked with the respective agreement number. By default, only active agreements are shown, however the menu item SCT $\rightarrow$ Show Active Agr and SCT $\rightarrow$ Show Not Active Agr makes switching between active and not active agreements possible. The difference is that the data of not active agreements are not subject to corrections.

Thus, each tab of the 'agreement' contains:

- the student's first, middle and family names;

- the full name of the course;

- information about fees and discounts;

- the starting date of the course;

- the duration of the course under the agreement;

- the teacher's first, middle and family names;
- the number of consultations in the videoconference mode under the agreement and the payment the teacher receives for each;

- the number of open tasks under the agreement and the payment the teacher receives for each;

- the payment to the supervisor of the educational programme;

- the number and the price of extra consultations in the video conference mode;

- an editable table with records of work under the agreement;

- a button that saves the current table with records of work under the agreement after corrections.

The editable table with records of work under the agreement also performs analysis of the entered data. When being filled the lower line of the table - coloured grey - shows the balance of the amount (payments for consultations, assessed open tasks, supervision).

Once zero value is reached (all expenses are paid) the background colour turns green. If the balance is in the red, the background colour turns red (Attention!). It makes work with a large number of agreements easier.

The fact that the module analyzes data and thus contributes to decision-making brings it closer to expert systems, the most essential property of which is storing and structuring knowledge [9, p. 33].

The CSTTables tab has a single button with help of which it is possible to save all tables that account for all works under all active agreements. The 'teachers' $\rightarrow$ 'Active Teachers' menu item forms a TXT file, that contains a list of all teachers who are currently working under agreements with a specific reference to the agreement number, the student's family name and a short name of the course. This information is necessary, for instance, every time payment orders for certain periods are prepared. The 'teachers' $\rightarrow$ 'Assignments Graded' menu item forms a TXT file that contains a full account of the work done by a certain teacher within a certain period of time. Let us now consider this function of the application more closely.

A drawback of the standard version of LMS Moodle 3.0 is the inflexibility of the report about the operations performed in the system, which is the result of the protocoling subsystem disadvantage. The thing is that the choice of the time range is limited either by a concrete date or by all days at once, which is rather inconvenient as a day's report is not informative and a report on the whole period is excessive. Partially this problem can be solved by means of reducing the period of time during which logs are stored, for instance 365 days or 180 days. However, this decision can lead to loss of data, which is why it is not that satisfactory.

Our task was to track how many open tasks had been assessed by a teacher within a certain period of time. To accomplish the task a report was generated that relied on the following settings: System $\rightarrow$ All participants $\rightarrow$ All days $\rightarrow$ All activities $\rightarrow$ Update $\rightarrow$ Teaching $\rightarrow$ Standard log. The option in bold type is the only possibility to limit the selection. Besides, the final report is loaded from the web server as a CSV file with commas acting as delimiters (Comma Separated Values 
text file). Finally, the received file is processed to detect open tasks and to delete duplications (in case the same task was assessed more than once, after mistakes correction, for instance).

At the next stage special TXT files that contain a list of teacher's consultations in the videoconference mode are processed in search of files that refer to the chosen period of time. Finally, there appears a report in form of a TXT file that reflects the time span with all dates for each teacher:

- the date and the time of each assessed open task for each student with the name of this task;

- the date and the time of each consultation in the videoconference mode with reference to each student;

- the overall number of assessed open tasks and consultations of each teacher.

This kind of report is the basis for compiling financial statements according to which teachers get their pay for a concrete period of work in the IEVE.

The Financial $\rightarrow$ General Report menu item mainly serves to generate the content of the Report tab that provides the following information:

- the number and the value of active agreements;

- the number and the value of performed agreements;

- the number and value of all agreements;

- the average value of one agreement;

- the annual report on all agreements.

The last one indicates the total number and the value of agreements performed each year (starting with the current year and downwards). The same scheme works for each month (from January to December) inside each year. Then follows a report on languages (the number and the value of agreements with regard to each language taught). Finally, there is a report on the courses (the number and the value of agreements with regard to each course). The button 'Printable General Report' under the main widget serves to generate a graphical report as an HTML file on the basis of all indicated data.

Another option of the overall financial report is the possibility of producing a monthly account of payments to teachers with indication of the number of each agreement, the number of consultations and assessed tasks.

The Financial $\rightarrow$ Month's Payments menu item produces a file that contains an HTML file with graphical account of monthly payments to teachers in accordance with all kind of agreements.

The tables 'course' (an account of current courses), 'coursesforteacher' (an account of concluded agreements), 'student' (an account of students) and 'teacher' (an account of teachers) have the option of correcting entries with immediate updates of all related tables without restarting the programme.

The described module helps to carry out the mainstreaming of the managing body work and take timely measures (produce all kind of drafts and documents). The programming code of the application is about 3000 lines long [10].

The time during which the described application was tested and used reveals noticeable improvements in the quality of documents, transparency of management, scaling-up, which leads to a substantial rise in the number of agreements with a minimum increase in the number of the staff.

\section{Statistic Data}

Statistic data that reflect the work during the whole period are provided below.

The average fee for one course made up 21522 RUB.

The average fee of one of the total number of agreements with students made up 21760 RUB.

The most popular language turned out to be English with French, German and Spanish to follow (Please, refer to Chart 1$)^{*}$ :

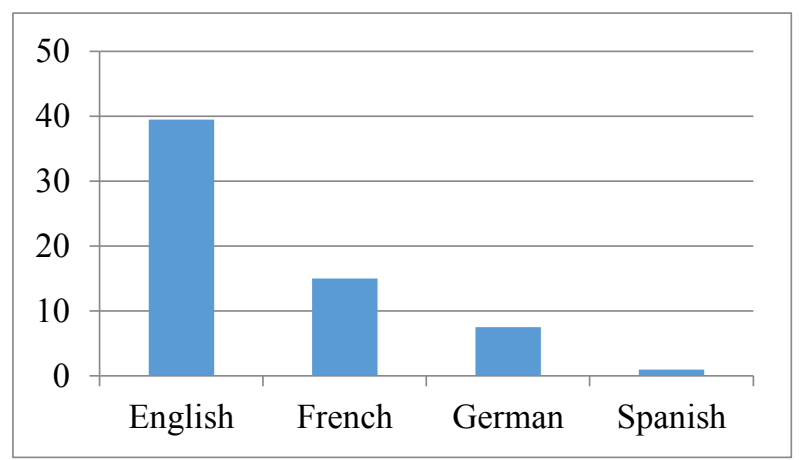

Chart 1. The relevance of courses in different languages.

Despite the fact that concluding an agreement and embarking on a course can take place practically any time of year, due to academic tradition the index reaches its highest point in September with its lowest point in March and July, and insignificant increases in November and February (Please, refer to Chart 2):

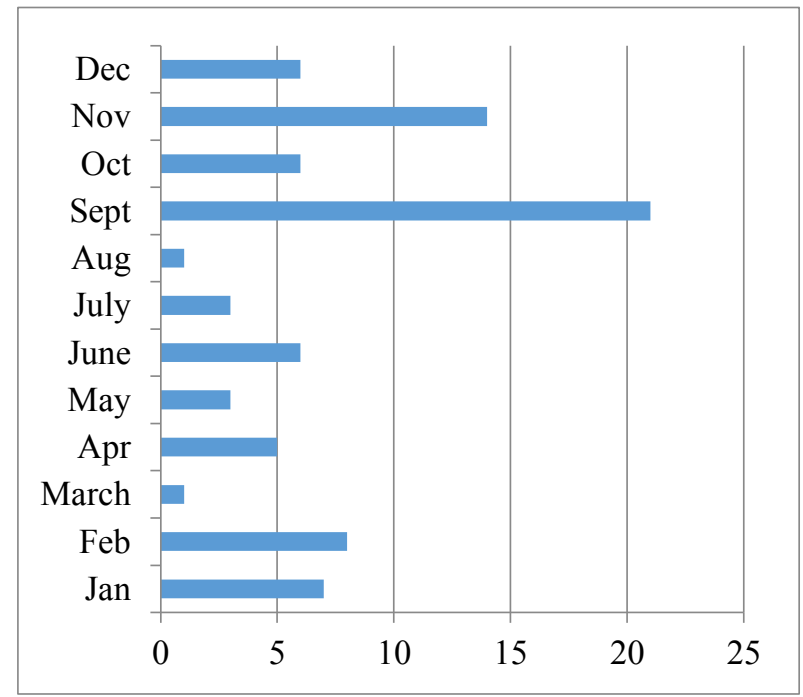

Chart 2. Monthly fluctuation of agreement making.

Here and further on all statistic information is presented in specific "units", that reflect relative, not absolute data. Thus, in Chart 1 the number of agreements for Spanish equals «1» 
Courses of Practical English prove to be the most popular with courses in Written Translation and courses in Communicative Grammar to follow (Please, refer to Chart 3):

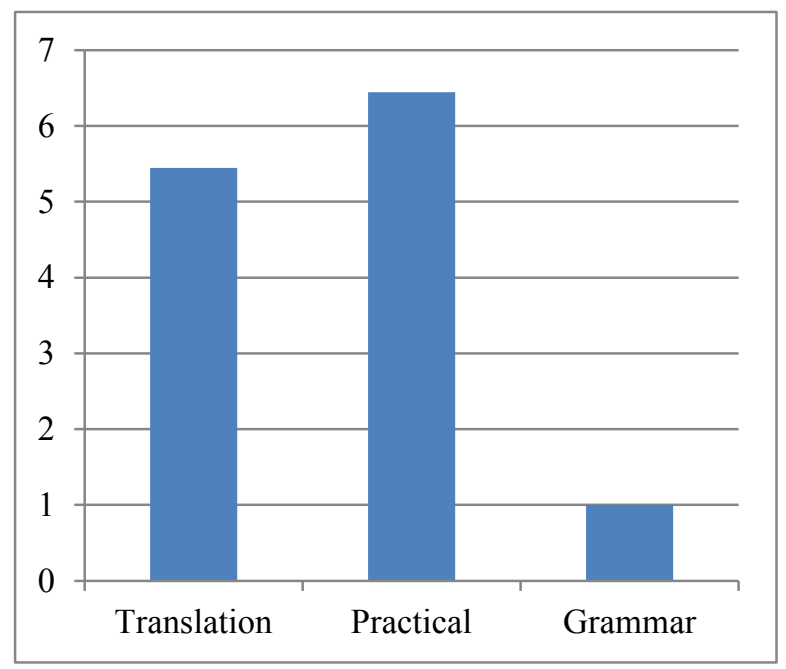

Chart 3. The relevance of different types of courses.

The most popular is the course «Written Translation of Mass Media Texts (advanced level of English). Stage 1. Language, Education, Arts» - 25,83\% of all agreements.

The share of students who successfully cope with the educational programme amounts to $94,35 \%$, which is a very high index. Less than $1 \%$ of all students successfully cope with the main part of the educational programme but refuse to take an exam.

The percentage of students who have accomplished more than one course is relatively high. (Please, refer to Chart 4):

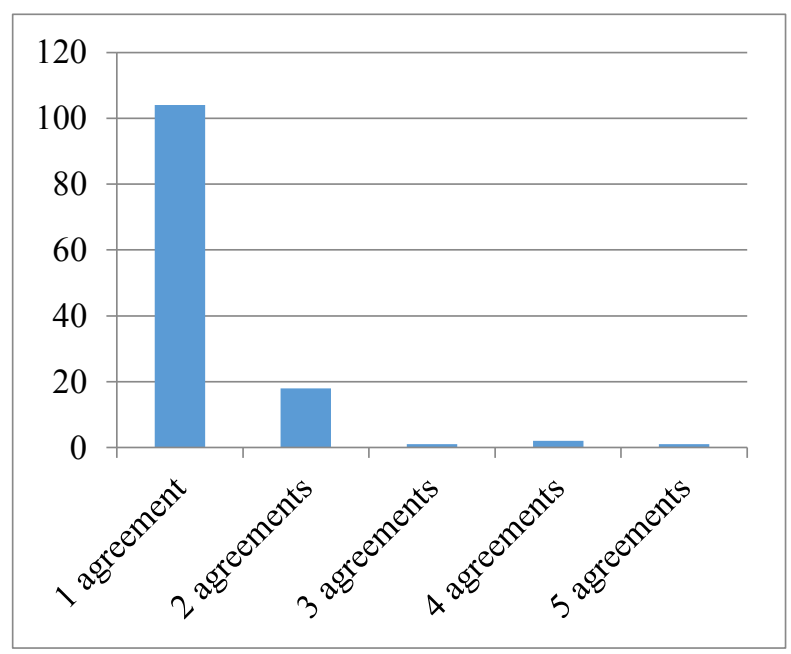

Chart 4. The relative percentage of students with more than one agreement.

The share of students who learn different foreign languages of all students who made more than one agreement is $3,22 \%$.

$45,97 \%$ of all students used $5-10 \%$ discounts for the courses mainly on the ground of having a diploma of higher education with honours, which proves that these students have developed great abilities of time management.

Only 3,23\% of all students used the opportunity of extra paid consultations, which goes to prove a proper balance between the number of consultations with the teacher and tasks for self study in educational programmes. In other words students tend to make an agreement for a new course instead of adding consultations in the mode of videoconferences to the course they are currently doing.

\section{Conclusion}

The achieved results prove that the adopted concept of distance learning is quite successful. The employed learning management system - Moodle 3, which was slightly modified programmatically and adjusted to the administrator's tools, has turned out to be a reliable instrument of teaching foreign languages.

Being unable to introduce large-scale open online courses worldwide but yet determined to implement more programmes and attract more students, MSLU research team came up with the decision to provide the earlier developed courses with opportunities of individual consultations in the videoconferencing mode, which is currently the most demanded service in the IEVE. The major reason for this popularity is the possibility of interpersonal contact with the teacher, which secures knowledge transfer from one individual to another and forms the basis of the learning process.

The commercial nature of the courses encourages the developers to pay more attention to the quality of the Elearning process and to meeting students' needs without converting education into fun or leisure time, which is often associated with IT-based learning. This approach helps to promote distance learning and teaches students to work independently and manage their time without ruining the basic principles of classroom education, namely the principle of communication (particularly between the teacher and the student) and the principles of reflection, personal growth, respect for human values, etc.

The results give reasons to believe that in terms of development prospects the major focus in the near future will be placed on increasing the number of taught languages and expanding the variety of educational programmes (with an important step being launching a programme of Russian as a foreign language), upgrading software products with a view to improving distant learning management.

\section{References}

1. P.Dillenbourg, Workshop on virtual learning environments by the University of Geneva, Virtual Learning Environments, Retrieved from: http://tecfa.unige.ch/tecfa/publicat/dil-papers2/Dil.7.5.18.pdf (2002)

2. Z.Strakova, I.Cimermanova, Electronic Journal Of E-Learning, Developing Reflective Skills of Student 
Teachers in the Virtual Learning Environment, 16, 107-121 (2018)

3. F.Kibaru, Turkish Online Journal Of Distance Education, Supporting Faculty To Face Challenges In Design And Delivery of Quality Courses In Virtual Learning Environments, 19, 176-197 (2018)

4. A.Zalizniak, Vestnik Rossiiskogo Universiteta Druzhby Narodov-Seriya Lingvistika-Russian Journal Of Linguistics, The Catalogue of Semantic Shifts: 20 Years Later, 22, 770-787 (2018)

5. P.Koch, Cognitive Linguistics Research, Meaning Change And Semantic Shifts. Lexical Typology Of Semantic Shifts, 58, 21-66 (2016)

6. B.Crespo, Anuari De Filologia-Estudis De Linguistica, Specialised Language Varieties: When A Cognitive Framework Can Explain Semantic Changes, 6, 63-85 (2016)
7. C.Girvan, ETR \& D-EDUCATIONAL TECHNOLOGY RESEARCH AND DEVELOPMENT, What is a virtual world? Definition and classification, 66, 1087-1100 (2018)

8. A.I.Gorozhanov, E.F.Kosichenko, I.A.Guseynova, SHS Web of Conferences, Teaching Written Translation Online: Theoretical Model, Software Development, Interim Results, 50, 01062 (2018)

9. R.K.Potapova, New Information Technologies in Linguistics (MSLU, Moscow, 2002)

10. A.I.Gorozhanov, The Joint Fund of Electronic Resources "Science and Education" at the Institute of Education Management of the Russian Academy of Education, Automatized Module for Management Distant Learning Process, License № 23823 from 18 October 2018 